\title{
A Cross-Sectional Study to Find Prevalence and Risk Factors for Childhood Asthma in Pune City, India
}

\author{
Maria Cheraghi, ${ }^{1}$ Alireza Dadgarinejad, ${ }^{2}$ and Sundeep Salvi ${ }^{3}$ \\ ${ }^{1}$ Department of Public Health, Ahvaz Jundishapur University of Medical Sciences, Ahvaz, Iran \\ ${ }^{2}$ Masjed Soleiman Azad University, Masjed Soleiman, Iran \\ ${ }^{3}$ Chest Research Foundation, Pune, India
}

Correspondence should be addressed to Maria Cheraghi, mariacheraghi@gmail.com

Received 8 November 2011; Accepted 8 December 2011

Academic Editor: A. Green

Copyright ( 92012 Maria Cheraghi et al. This is an open access article distributed under the Creative Commons Attribution License, which permits unrestricted use, distribution, and reproduction in any medium, provided the original work is properly cited.

We aimed to determine current prevalence of asthma and risk factors associated with it in Pune, India. Methods. This was a crosssectional school-population-based study in which parents of school children aged 6-7 and 13-14 were administered an ISAAC questionnaire and an additional set of questions that detected the presence of potential risk factors known to be associated with asthma during 2008-2009 academic years. Results. Prevalence of current asthma was 6.7\% (7\% amongst 6-7-year olds and 6.3\% amongst 13-14 year olds. Asthma was more common amongst boys (8.1\%) than girls (4.9\%) and more frequent in students studying in private schools $(7.3 \%)$ than in those studying in public schools $(5.8 \%)$. Risk factors such as family history of atopy, caesarian delivery, use of biomass fuel for cooking, absence of separate kitchen, absence of exclusive breastfeeding during the first 6 months of life, preterm birth, snoring, dampness at home, male sex, and parental smoking were significantly associated with asthma. Conclusion. There was a high prevalence of childhood asthma in Pune, India, which was associated with genetic and environmental risk factors.

\section{Introduction}

The prevalence of childhood asthma has grown dramatically in most western countries of the world [1-3] and has largely paralleled the growth in urbanization and industrialization [4]. In the developing countries although the prevalence of childhood asthma is reported to be lower, there is growing evidence to suggest that the prevalence is increasing alarmingly as it did in the western countries over 2-3 decades ago. Whether this is because of rapid urbanization, change in lifestyle, and increased levels of outdoor and indoor air pollution levels is not known.

The International Study of Asthma and Allergies in Childhood (ISAAC) is one study which has studied the prevalence of childhood asthma and the risk factors associated with it in more than 100 countries using a standardized study methodology. ISAAC studies have shown that asthma prevalence is much higher in industrialized and western countries as compared to developing countries such as Asia and Africa [5]. In 2003 the ISAAC study in the urban city of
Pune reported the prevalence of wheeze in the last 12 months to be $2.9 \%$ in school children aged 6-7 and 13-14 [6].

Pune is one of the fastest developing cities in India. The last decade has seen a remarkable growth in urbanization accompanied by a huge increase in the number of motor vehicles. This has led to a significant deterioration in the air quality. Moreover life style has also changed dramatically with increasing socioeconomic growth, which has parallel growth in weight, with obesity and overweight. A repeat ISAAC study performed after 5 years has shown an increase in childhood asthma prevalence in Pune city [6]. The aim of this study was to investigate the prevalence of childhood asthma in Pune city using the ISAAC protocol and also investigate the risk factors associated with childhood asthma.

\section{Methods}

This was a cross-sectional school-population-based study in which parents of school children aged 6-7 and 13-14 in Pune city were administered an ISAAC questionnaire and 


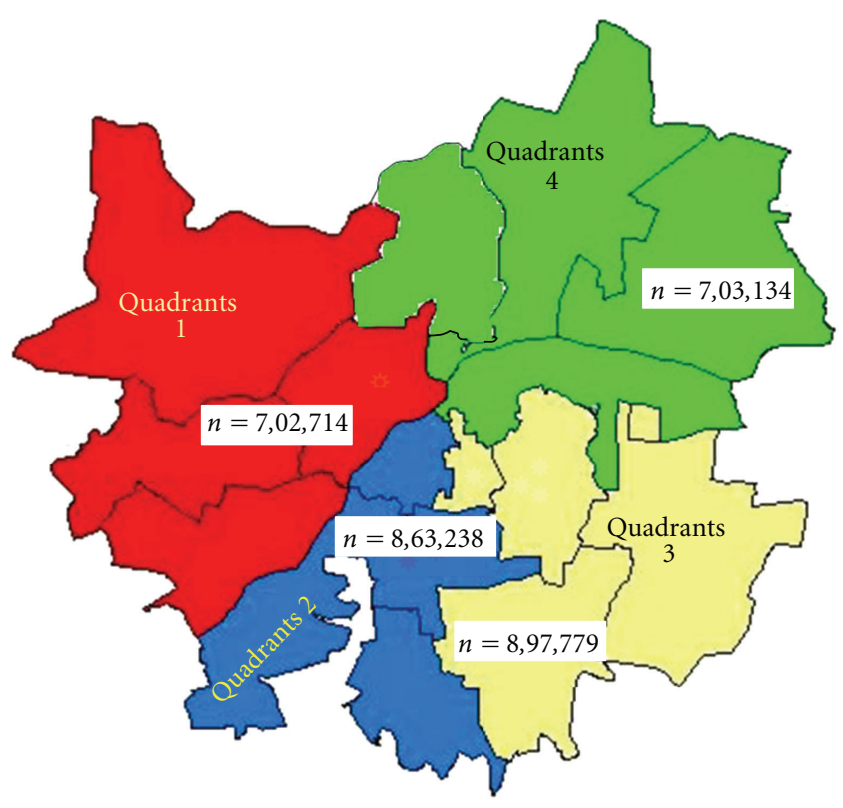

Figure 1: Map of Pune city divided into 4 quadrants, and location of schools.

an additional set of questions that detected the presence of potential risk factors known to be associated with asthma during the school academic year 2008-2009.

2.1. Study Population. School children aged 6-7 and 13-14 were randomly selected from schools from Pune city. There are a total of 462 schools in Pune. The schools are broadly divided into two categories: public schools $(n=242)$ and private schools $(n=240)$. We then divided Pune into 4 zones (from the 14 geographical wards) with roughly similar total population size (Figure 1). List of governmental registered schools from each zone was procured. Then, with simple random sampling, 4 schools from each zone were selected to make a total of 16 schools of which 8 were private and 8 were public. All the 6198 children between age group 67 and 13-14 studying in those schools represented children from various socioeconomic strata. Their age was confirmed as per school records. The study was approved by the local independent ethics committee before the start of the study.

Prior permissions from educational authorities, school principals, and class teachers were obtained, and then children between the ages of 6-7 and 13-14 studying in those schools were invited to participate in this study.

2.2. Research Tools. The International Study of Asthma and Allergies in Childhood (ISAAC) questionnaire were used as a tool to identify prevalence of asthma. This tool has been validated worldwide and has been used to determine asthma prevalence in more than two million children, so far. An additional set of questions that detected the information on potential risk factors associated with asthma were also added. These included environmental exposures (students' residency close to busy roads, parental smoking, type of cooking fuels, presence or absence of separate kitchen, type of house, ventilation, presence of wall dampness, presence of cockroaches and pets at home, weight at birth, birth order, presence of preterm birth, type of delivery, mother's age at the time of delivery, breastfeeding during first 6 months of life, vaccination, type of family, number of family members, number of siblings, eating habits, snoring during sleep, parental education, parental occupation, and annual income of family. The parents of study children were given a written information sheet that explained the purpose of the study and invited to complete the questionnaire after they gave their written informed consent. An additional set of questions related to the demography of schools and classroom environment like type of school, age of school, school distance from main road, presence of dampness in the classroom, presence of ventilation, and number of students in the classroom were directly filled out by the research team after consultation with the class teacher and school principal.

The original draft of parents' information sheet, consent form, and validated questionnaire were made in English and translated into the local language (Marathi) by an expert in this subject. The Marathi translation was subsequently back translated into English, which has been done by three different categories of people (a professional doctor, a qualified non-medical graduate, and a lay person).

For private schools, the parents' information sheet, consent form, and the questionnaire were distributed to the children with a request to get it signed and filled out by their parents or guardians at home. For children studying in public school, who usually represent children from lower and middle socioeconomic strata, a meeting was arranged with the parents with the help of the school teacher and principal as we anticipated that parents would be less educated. During this meeting, the study questionnaire and consent form were distributed. After obtaining their informed consent, the questionnaires were directly administered by the research staff to the parents with the help of the class teacher.

Asthma in the study population was defined as per the ISAAC study criteria, namely, "presence of wheezing or whistling in the chest, chest sounded wheezy during or after exercise, and dry cough at night; apart from a cough associated with a cold or chest infection" during the past 12 months, or if they answered "yes" to the question "has your child ever had asthma?".

2.3. Pilot Study. Before the start of the main study, we conducted a pilot study in 1000 children studying in 3 public schools and 2 private schools, who were from different socioeconomic status in Pune city. Pilot study helps us to understand the logistic difficulties during the conduct of the study, to determine sample size for main study, to estimate the response rate, and also to study the parents' difficulties to understand how to fill in the questionnaire.

2.4. Statistical Analysis. A sample size of 3800 was calculated based on the results of the pilot study conducted by us on 1000 school children in Pune, which has shown that 
the prevalence of asthma in school children was 5\%. The following formula was used for calculating the sample size:

$$
n \approx 4 * p * \frac{q}{L^{2}} \longrightarrow n \approx 4 * 0.05 * \frac{0.95}{(0.01)^{2}}=1900 .
$$

A sample size of 1900 for age group 6-7 years and 1900 for age group 13-14 years were estimated; therefore, a precision value of $99 \%$ was given.

All the data collected from the returned questionnaires was double-entered by data input clerks into Epi-Info. The data set were then validated and consolidated by a single data manager. Prevalence of asthma in the study population was as the percentage of children having defined of asthma symptoms, based on preset definition. A subsequent descriptive analysis was performed to study agewise, sexwise, and school-type-wise prevalence of asthma.

A bivariate analysis was then performed to identify possible potential risk factors associated with asthma, as reflected by significant chi-square test. Logistic regression analysis was then used to determine the various potential risk factors associated with asthma. The impact of the risk factors was described in terms of the odds ratio and adjusted odds ratio along with confidence intervals. All the analysis was performed using SPSS (17) statistical analysis software.

\section{Results}

The questionnaires were distributed to a total of 6198 parents of children from 16 schools, out of which 4179 parents consented and completed the questionnaire. 270 questionnaires were filled in, but without signing the consent forms. These were excluded from the analysis. A total number of 3909 children were therefore used for final analyses. These included 1990 children aged 6-7 years and 1919 children aged 13-14 years (Figure 2).

3.1. Prevalence. The overall prevalence of childhood asthma as reported by parents was $6.7 \%$. Prevalence of asthma in those between 6-7 years of age was $7.0 \%$ and $6.3 \%$ in those between 13-14 year of age. Overall, boys had a higher prevalence as compared to girls (8.1\% versus $4.9 \%$, resp.). Prevalence of asthma amongst children studying in public schools was $5.8 \%$, and in those studying in private schools was $7.3 \%$ (Figure 3 ).

The overall prevalence of ever experiencing wheeze was $9.5 \%$, wheeze in the past 12 months was $5.4 \%$, ever having asthma was $5.6 \%$, chest sounded wheezy after exercise was $9.5 \%$, and dry cough at night was $15.9 \%$. The most common asthma symptom was therefore dry cough at night. Out of the total prevalence of $6.7 \%$, only $5.6 \%$ children answered "yes" to the question "has your child ever had asthma?" (Figure 4).

3.2. Risk Factors. Unadjusted odds ratio showed that having family history of atopy, birth by caesarian delivery, preterm birth, male gender, absence of exclusive breast feeding during first 6 months of life, snoring during sleep, presence of smoker at home, absence of separate kitchen, presence of

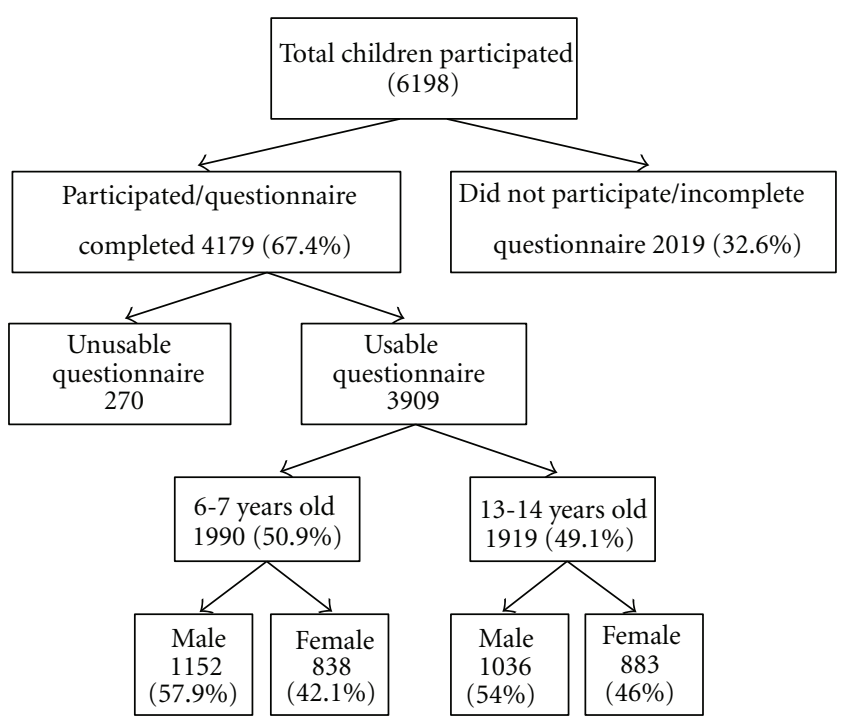

FIgURE 2: Questionnaire response rate for the study.

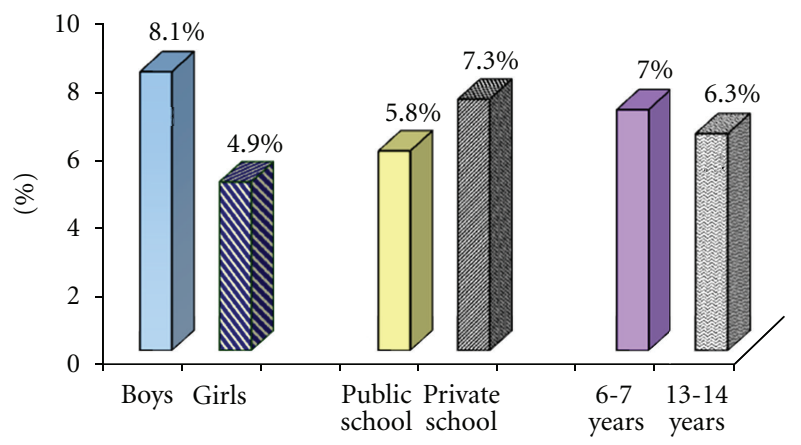

FIgure 3: Overall prevalence of childhood asthma in Pune city.

damp walls, cockroaches at home, living in Kutcha (means mud or temporary) house, use of biomass fuel for cooking, residency close to busy roads, and distance of school $\leq 300$ meters from main road were all significantly associated (all $<0.05$ ) with childhood asthma (Table 1).

Using the logistic regression model, a positive family history of atopy emerged to be the strongest risk factor for development of asthma (adj. OR: 6.55; CI: 4.59-9.35), while birth by caesarian delivery was identified as the second strongest risk factor associated with childhood asthma. Childhood asthma was also significantly associated with other risk factors after adjustment and included preterm birth (adj. OR: 1.92; CI: 1.24-3.00), absence of exclusive breast feeding during first 6 months of life (adj. OR: 1.97; CI: 1.37-2.83), presence of smoker at home (adj. OR: 1.48; CI: 1.00-2.20), absence of separate kitchen (adj. OR: 2.33; CI: 1.35-4.02), presence of dampness at home (adj. OR: 1.59; CI: 1.07-2.38), male gender (adj. OR: 1.54; CI: 1.05-2.25), use of biomass fuel for cooking (adj. OR: 2.49; CI: 1.07-8.04) and snoring during sleep (adj. OR: 1.8; CI: 1.21-2.84) (Table 1). 
Table 1: Risk factors for childhood asthma in Pune city.

\begin{tabular}{|c|c|c|c|c|}
\hline Risk factors & $\begin{array}{c}\text { Overall } \\
\text { population OR } \\
(95 \% \mathrm{CI})\end{array}$ & $P$ value & $\begin{array}{l}\text { Overall population } \\
\text { adj. OR }(95 \% \mathrm{CI})\end{array}$ & $P$ value \\
\hline Family history & $9.1(6.9-11.8)$ & $<0.0001$ & $6.55(4.59-9.35)$ & $<0.0001$ \\
\hline Caesarian delivery & $3.9(3.0-5.1)$ & $<0.0001$ & $3.84(2.67-5.54)$ & $<0.0001$ \\
\hline Preterm birth & $3.9(3.0-5.1)$ & 0.001 & $1.92(1.24-3.00)$ & 0.001 \\
\hline Snoring at night & $3.6(2.7-4.7)$ & $<0.0001$ & $1.85(1.21-2.84)$ & $<0.0001$ \\
\hline Use of biomass fuel & $2.59(1.69-3.99)$ & $<0.0001$ & $2.94(1.07-8.04)$ & $<0.0001$ \\
\hline Absence of exclusive breast feeding during first 6 months of life & $2.5(1.90-3.30)$ & $<0.0001$ & $2.33(1.35-4.02)$ & $<0.0001$ \\
\hline Smoker at home & $2.4(1.80-3.10)$ & 0.002 & $1.48(1.00-2.20)$ & 0.002 \\
\hline Absence of separate kitchen & $2.2(1.67-2.94)$ & $<0.0001$ & $2.33(1.35-4.02)$ & $<0.0001$ \\
\hline Presence of dampness at home & $2.2(1.70-2.9)$ & $<0.0001$ & $1.59(1.07-2.38)$ & $<0.0001$ \\
\hline Male gender & $1.7(1.30-2.20)$ & $<0.0001$ & $1.54(1.05-2.25)$ & $<0.0001$ \\
\hline Residence near to busy road & $1.7(1.19-2.64)$ & 0.007 & $*$ & $*$ \\
\hline Living in Kutcha house & $1.6(1.00-2.60)$ & 0.050 & $*$ & $*$ \\
\hline Presence of cockroaches at home & $1.7(1.30-2.30)$ & $<0.0001$ & $*$ & $*$ \\
\hline
\end{tabular}

CI: confidence Interval.

OR: odds Ratio.

adj. OR: adjusted odds ratio.

$*$ : not significant.

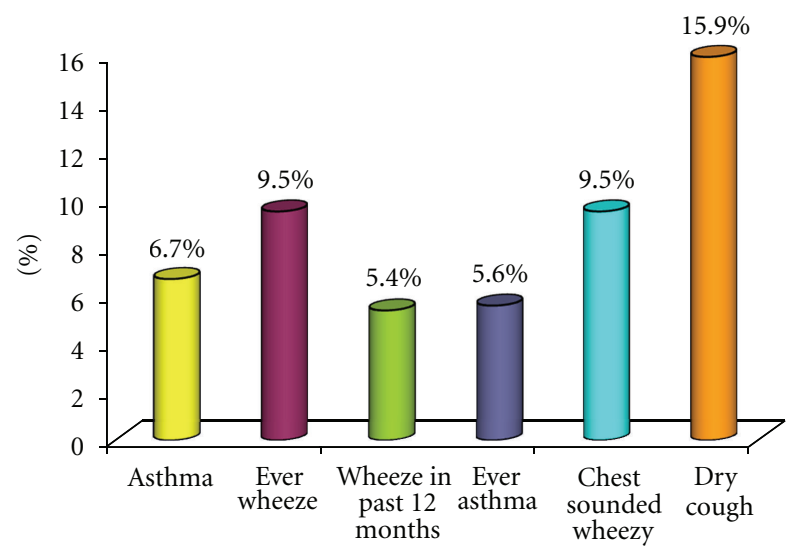

FIGURE 4: Prevalence of respiratory symptoms in children age 6-7 \& 13-14 in Pune city.

\section{Discussion}

The prevalence of childhood asthma as defined by the ISAAC study protocol in this study was (6.7\%) with no significant difference between children aged 6-7 years $(7 \%)$ and those aged $13-14$ years $(6.3 \%)$. Childhood asthma was more common among boys $(8.1 \%)$ than girls $(4.9 \%)$. The observations that asthma is more prevalent amongst boys during childhood has been reported in several earlier studies [7, 8]; similar findings were reported from India [9], Italy [10], United Arab Emirates [11], and Iran [12]. The reason for male gender predominance during childhood is not known. It would be due to genderwise difference in airways patency due to hormonal differences.
An earlier study conducted in the city of Pune using the same study protocol in 8000 children (part of ISAAC phase III) reported a prevalence of $2.9 \%$ [6]. This study was conducted in 2003-2004. Our study which was conducted in 2008-2009 using the same study methodology reported an overall prevalence of childhood asthma of 5.4\%, which is $80 \%$ higher [6]. Almost a doubling in the prevalence of childhood asthma over a short time period of 5 years is certainly worrisome and needs further investigation. It seems likely that rapid changes in the demographics of Pune city, such as increased urbanization, increased vehicular traffic density, and adaptation of western life style may have been responsible.

The prevalence of asthma was more common in children studying in private schools $(7.3 \%)$, which represent relatively higher socioeconomic status as compared to children studying in public schools (5.8\%), which mainly represent children from lower socioeconomic status. Children from the lower socioeconomic strata live in homes that are smaller and more overcrowded and were subjected to a greater exposure to microorganism, than children from high socioeconomic strata. These observations are in accordance with the hygiene hypothesis [13]. It could also be possible that children from the relatively higher socioeconomic class may be exposed to sociocultural factors that increase the risk of developing asthma. These include consumption of junk food and lack of physical exercise. With less physical activity, they are more likely to be obese. There is evidence to suggest that obesity is significantly associated with asthma, and there are arguments to support a causal relationship [14].

A family history of atopy and asthma was the strongest risk factor associated with childhood asthma, with an adjusted odds ratio of 6.55 (CI: 4.59-9.35). Earlier studies 
from different parts of the world have also reported a strong association between family history of atopy and asthma with reported prevalence of asthma from Australia [15], Scotland [16], Taiwan [17], and Sweden [18]. The strength of the association between family history of atopy and asthma observed in our study clearly highlights the fact that family history is indeed an important risk factor for asthma. Although asthma is known to run in families, the identification of an asthma gene has been elusive with over 100 genes found to be associated with asthma.

Caesarian section was the second largest risk factor associated with childhood asthma in our study (adj. OR: 3.84; CI: 2.67-5.54). This association has been previously reported from different studies from several countries [19$22]$. The strength of the association reported in our study and the consistency of the observation made across different parts of the world seem to argue for a causal relationship. Although we do not yet know the mechanisms by which caesarian deliveries may be linked with risk of developing asthma, it has been suggested that babies born by normal vaginal delivery swallow the microbial flora that colonizes the vaginal mucosa of the mother, which has been shown to stimulate the immune system to deviate towards a stronger Th1 direction than those born by the caesarian delivery who essentially have a sterile delivery $[23,24]$.

Our study demonstrated a significant association between the type of fuel used for cooking and the prevalence of childhood asthma. Children who lived in homes that used biomass or kerosene fuel showed a higher prevalence of asthma as compared to those children who lived in homes that used liquefied petroleum gas for cooking (adj. OR: 2.94, CI: 1.07-8.04). These observations are in accordance with earlier published studies [25-27]; while some have reported no association [28], others found a protective effect [29]. Use of biomass or kerosene is associated with higher levels of particulate and gaseous indoor air pollution [30], and studies have shown that indoor air pollution is indeed a strong risk factor associated with childhood asthma [31-35]. Although these observations have been reported in other countries, the strength of the association noted in our study suggests a true causal association.

Childhood asthma was also associated with the absence of a separate kitchen at home (adj. OR: 2.33, CI: 1.354.02). This is a novel observation, which highlights the fact that the kitchen is an important determinant of lung health. We have earlier reported that people living in homes with no separate kitchen had a 2.5-fold greater odds of having COPD (Brashier B. abstract submitted to European Respiratory Society, 2008). People who live in single-room homes where the kitchen and the living room are in the same area would be exposed to higher levels of indoor air pollution due to cooking. There are several other sources of indoor air pollutants, which may compound the effects of cooking generated pollutants, such as the burning of mosquito coil, burning of increase, and passive smoking.

In accordance with earlier reported studies [36, 37], we found that children who were not exclusively breastfed showed a stronger association with asthma (adj. OR: 1.97, CI: $1.37-2.83$ ) as compared to those who were exclusively on breast milk for the first 6 months of their life. This association was especially stronger amongst the 13-14-year old children (adj. OR: 3.15, CI: 1.85-5.37). The results of this study add support to the growing body of evidence that shows that breastfeeding is likely to be protective against childhood asthma [36-39]. The mechanism of the effect of breastfeeding on asthma is, however, not clear. This could be due to the immunological and nutritional benefits of human milk [40, 41]. Specific components in human milk have been suggested to promote the maturation of the immune system, such as large numbers of active white cells which release biologically active chemicals into the digestive system and surrounding tissues that have the potential to influence the developing immune system $[42,43]$. Furthermore, it has been shown that lung development is aided by a number of growth factors found in human milk [39].

We observed that children aged 6-7 born with lownormal gestational age ( $<36$ weeks) had a $92 \%$ greater risk of having asthma (adj. OR: 1.92 CI: 1.24-3.00) as compared to those born with normal gestational age. However, this association was not found in children aged 13-14. This observation is in conformity with earlier reported studies $[44,45]$ and extends our understanding of the relationship between gestational age and asthma. It is clear from previous studies that children with bronchopulmonary dysplasia and severe respiratory illnesses attributable to premature birth often experience persistent airway hyperresponsiveness and symptoms consistent with asthma. Babies born prematurely may have poorly developed airways and delicate lungs that may make them susceptible to develop asthma $[46,47]$.

Another novel observation in our study was that children who were reported to habitually snore had a significantly greater odds of having associated asthma (adj. OR: 1.85; CI: 1.21-2.84). There are very few studies that have investigated this association $[48,49]$. with some reporting a higher prevalence of asthma amongst frequent snorers [50,51]. There are a number of potential mechanisms by which asthma and snoring might be linked. An increased drive to breathe deeply during sleep in active asthma can lead to increased upper airway suction pressures, leading to snoring. Alternatively, worsening of gastroesophageal reflux induced by snoring may also trigger asthma [51]. However, we did not gather information about gastroesophageal reflux in the present study. The upper airway vibration can stimulate upper airway cough receptors and induce reflex bronchoconstriction, which has been demonstrated in an animal model [52]. Also, snoring might play a more direct role in the underlying pathology of asthma. The upper airway vibration and increased suction pressures in the pharynx are powerful mechanisms that promote the transfer of nasal mucus into the lower airways. Clearly, transfer of such material onto the glottis inlet can induce cough by the stimulation of glottis cough receptors. However, this same mechanism has the potential to deliver relatively large quantities of mucus, laden with key allergens, such as house dust mite, into the airways and could contribute to develop asthma or it may be a simple comorbid condition associated with asthma [49].

Presence of damp walls at home was associated with increased prevalence of childhood asthma (adj. OR: 1.59, 
CI: 1.07-2.38). A series of large-population-based epidemiologic studies [53-55] have reported consistent associations between dampness and mold in the home and the risk of asthma or wheezing in children. A review of 61 studies in children and adults concluded that dampness of walls is indeed a significant risk factor for cough, wheeze, and asthma [56]. The specific causal agents related to indoor dampness are not well understood. However, studies indicate that molds may grow in these damp walls and induce immunoglobulin-E-mediated hypersensitivity reactions toxic reactions caused by mycotoxins along with nonspecific inflammatory reactions caused by irritating volatile organic compounds produced by microbes on cell wall components, such as 1,3- $\beta$-D-glucan and ergosterol [ 57 , 58]. It has been shown that different species of fungi induce asthma by different mechanisms [59]. We have reported earlier that homes of asthmatic children have 2-fold greater amounts of fungi in the air as compared to homes of nonasthmatic children (Mandrekar S. abstract submitted to European Respiratory Society, 2008).

Children exposed to passive smoke at home had a $48 \%$ increased prevalence of asthma (adj. OR: 1.48, CI: 1.002.20). Numerous studies have suggested that exposure to tobacco smoke is indeed an important risk factor for the development of childhood asthma $[26,60]$.

\section{Conclusion}

The prevalence of asthma has grown dramatically in the city of Pune in the last 5 years, most likely due to growing urbanization, modernization, overcrowding, growing motor vehicular exhaust air pollutants, and changing lifestyles. These observations seem to follow those that were earlier reported in developed countries several decades ago, suggesting that modernization and urbanization are indeed a driving force for increasing asthma prevalence.

This is one of the first studies in India that has identified the presence of several risk factors associated with childhood asthma. Whilst questionnaire-based studies such as this do have certain drawbacks, identification of these risk factors paves a new way forward to understand asthma better in India. Some of the risk factors identified in this study such as having family history of atopy and asthma, male gender, presence of damp walls at home, smoker at home, preterm delivery, and absence of exclusive breast feeding during first six months of life have been reported in earlier studies from across the world and therefore reiterate the importance of these risk factors for asthma even in an Indian context. Moreover, this study also identified novel risk factors associated with asthma that have not been reported earlier in the Indian population such as absence of separate kitchen, caesarian delivery, snoring during sleeping, and use of biomass fuel for cooking. Identification of these risk factors as reported in this study has several public health applications. These observations need to be replicated in future studies across the country to understand regional or geographic variations. Whilst the associations that we have reported do not imply direct causal relationships, they offer some evidence of potential risk factors that could or need to be avoided to prevent the development of childhood asthma in India, so that asthma can be prevented in the subsequent generation.

\section{Acknowledgments}

The authors' sincere gratitude is extended to all of the parents and children who participated in the study. This research was supported by the Chest Research Foundation, Pune, India.

\section{References}

[1] H. R. Anderson, R. Gupta, D. P. Strachan, and E. S. Limb, “50 Years of asthma: UK trends from 1955 to 2004," Thorax, vol. 62, no. 1, pp. 85-90, 2007.

[2] P. J. Mandhane, J. M. Greene, J. O. Cowan, D. R. Taylor, and M. R. Sears, "Sex differences in factors associated with childhoodand adolescent-onset wheeze," American Journal of Respiratory and Critical Care Medicine, vol. 172, no. 1, pp. 45-54, 2005.

[3] B. G. Toelle, K. Ng, E. Belousova, C. M. Salome, J. K. Peat, and G. B. Marks, "Prevalence of asthma and allergy in schoolchildren in Belmont, Australia: three cross sectional surveys over 20 years," British Medical Journal, vol. 328, no. 7436, pp. 386-387, 2004.

[4] R. Beasley, J. Crane, C. K. W. Lai, and N. Pearce, "Prevalence and etiology of asthma," Journal of Allergy and Clinical Immunology, vol. 105, no. 2, pp. S466-S472, 2000.

[5] M. Mvula, M. Larzelere, M. Kraus et al., "Prevalence of asthma and asthma-like symptoms in inner-city schoolchildren," Journal of Asthma, vol. 42, no. 1, pp. 9-16, 2005.

[6] M. I. Asher, S. Montefort, B. Björkstén et al., "Worldwide time trends in the prevalence of symptoms of asthma, allergic rhinoconjunctivitis, and eczema in childhood: ISAAC Phases One and Three repeat multicountry cross-sectional surveys," The Lancet, vol. 368, no. 9537, pp. 733-743, 2006.

[7] E. M. Taveras, C. A. Camargo, S. L. Rifas-Shiman et al., "Association of birth weight with asthma-related outcomes at age 2 years," Pediatric Pulmonology, vol. 41, no. 7, pp. 643-648, 2006.

[8] W. J. Morgan and F. D. Martinez, "Risk factors for developing wheezing and asthma in childhood," Pediatric Clinics of North America, vol. 39, no. 6, pp. 1185-1204, 1992.

[9] S. Pakhale, K. Wooldrage, J. Manfreda, and N. Anthonisen, "Prevalence of asthma symptoms in 7th- and 8th-grade school children in a rural region in India," Journal of Asthma, vol. 45, no. 2, pp. 117-122, 2008.

[10] R. Ronchetti, M. P. Villa, M. Barreto et al., "Is the increase in childhood asthma coming to an end? Findings from three surveys of schoolchildren in Rome, Italy," European Respiratory Journal, vol. 17, no. 5, pp. 881-886, 2001.

[11] S. Alsowaidi, A. Abdulle, and R. Bernsen, "Prevalence and risk factors of asthma among adolescents and their parents in AlAin (United Arab Emirates)," Respiration, vol. 79, no. 2, pp. 105-111, 2009.

[12] B. MirSaeid Ghazi, S. H. Sharifi, and K. Goodarzipoor, "The prevalence of asthma among the students (7-18 Years Old) in Tehran during 2002-2003," Iranian Journal of Allergy, Asthma and Immunology, vol. 3, no. 2, pp. 89-92, 2004.

[13] S. S. Salvi and S. T. Holgate, "Is there a link between hygiene and allergic disease?” Microbiology Today, vol. 28, pp. 175-177, 2001. 
[14] S. Chinn, R. J. Rona, S. T. Weiss, and S. Shore, "Obesity and asthma in children," American Journal of Respiratory and Critical Care Medicine, vol. 170, no. 1, pp. 95-96, 2004.

[15] M. A. Jenkins, J. L. Hopper, L. B. Flander, J. B. Carlin, and G. G. Giles, "The associations between childhood asthma and atopy, and parental asthma, hay fever and smoking," Paediatric and Perinatal Epidemiology, vol. 7, no. 1, pp. 67-76, 1993.

[16] G. L. Christie, P. J. Helms, D. J. Godden et al., "Asthma, wheezy bronchitis, and atopy across two generations," American Journal of Respiratory and Critical Care Medicine, vol. 159, no. 1, pp. 125-129, 1999.

[17] Y. L. Lee, Y. C. Lin, T. R. Hsiue, B. F. Hwang, and Y. L. Guo, "Indoor and outdoor environmental exposures, parental atopy, and physician-diagnosed asthma in Taiwanese schoolchildren," Pediatrics, vol. 112, no. 5, article e389, pp. 389-389, 2003.

[18] E. Rönmark, E. Jönsson, T. Platts-Mills, and B. Lundbäck, "Different pattern of risk factors for atopic and nonatopic asthma among children-report from the obstructive lung disease in northern Sweden study," Allergy, vol. 54, no. 9, pp. 926-935, 1999.

[19] P. Bager, M. Melbye, K. Rostgaard, C. S. Benn, and T. Westergaard, "Mode of delivery and risk of allergic rhinitis and asthma," Journal of Allergy and Clinical Immunology, vol. 111, no. 1, pp. 51-56, 2003.

[20] T. M. McKeever, S. A. Lewis, C. Smith et al., "Early exposure to infections and antibiotics and the incidence of allergic disease: a birth cohort study with the West Midlands General Practice Research Database," Journal of Allergy and Clinical Immunology, vol. 109, no. 1, pp. 43-50, 2002.

[21] B. Xu, J. Pekkanen, A. L. Hartikainen, and M. R. Järvelin, "Caesarean section and risk of asthma and allergy in adulthood," Journal of Allergy and Clinical Immunology, vol. 107, no. 4, pp. 732-733, 2001.

[22] B. Xu, J. Pekkanen, and M. R. Jarvelin, "Obstetric complications and asthma in childhood," Journal of Asthma, vol. 37, no. 7, pp. 589-594, 2000.

[23] M. M. Gronlund, H. Arvilommi, P. Kero, O. P. Lehtonen, and E. Isolauri, "Importance of intestinal colonisation in the maturation of humoral immunity in early infancy: a prospective follow up study of healthy infants aged 0-6 months," Archives of Disease in Childhood, vol. 83, no. 3, pp. F186-F192, 2000.

[24] M. M. Grönlund, O. P. Lehtonen, E. Eerola, and P. Kero, “Fecal microflora in healthy infants born by different methods of delivery: permanent changes in intestinal flora after cesarean delivery," Journal of Pediatric Gastroenterology and Nutrition, vol. 28, no. 1, pp. 19-25, 1999.

[25] X. Xu, T. Niu, D. C. Christiani et al., "Occupational and environmental risk factors for asthma in rural communities in China," International Journal of Occupational and Environmental Health, vol. 2, no. 3, pp. 172-176, 1996.

[26] J. Thorn, J. Brisman, and K. Torén, "Adult-onset asthma is associated with self-reported mold or environmental tobacco smoke exposures in the home," Allergy, vol. 56, no. 4, pp. 287292, 2001.

[27] R. Pistelly, "Wood smoke and asthma: a controversial issue," American Journal of Respiratory and Critical Care Medicine, vol. 155, p. A941, 1997.

[28] W. C. Maier, H. M. Arrighi, B. Morray, C. Llewellyn, and G. J. Redding, "Indoor risk factors for asthma and wheezing among Seattle school children," Environmental Health Perspectives, vol. 105, no. 2, pp. 208-214, 1997.
[29] R. E. Volkmer, R. E. Ruffin, N. R. Wigg, and N. Davies, "The prevalence of respiratory symptoms: in south australian preschool children. II. Factors associated with indoor air quality," Journal of Paediatrics and Child Health, vol. 31, no. 2, pp. 116-120, 1995.

[30] R. A. Etzel, "Indoor air pollution and childhood asthma: effective environmental interventions," Environmental Health Perspectives, vol. 103, no. 6, pp. 55-58, 1995.

[31] D. G. Fullerton, N. Bruce, and S. B. Gordon, "Indoor air pollution from biomass fuel smoke is a major health concern in the developing world," Transactions of the Royal Society of Tropical Medicine and Hygiene, vol. 102, no. 9, pp. 843-851, 2008.

[32] T. Fujii, S. Hayashi, J. C. Hogg, R. Vincent, and S. F. Van Eeden, "Particulate matter induces cytokine expression in human bronchial epithelial cells," American Journal of Respiratory Cell and Molecular Biology, vol. 25, no. 3, pp. 265-271, 2001.

[33] H. Mukae, R. Vincent, K. Quinlan et al., "The effect of repeated exposure to particulate air pollution (PM10) on the bone marrow," American Journal of Respiratory and Critical Care Medicine, vol. 163, no. 1, pp. 201-209, 2001.

[34] D. Behera, T. Chakrabarti, and K. L. Khanduja, "Effect of exposure to domestic cooking fuels on bronchial asthma," The Indian Journal of Chest Diseases \& Allied Sciences, vol. 43, no. 1, pp. 27-31, 2001.

[35] E. R. Bleecker, "Similarities and differences in asthma and COPD: the Dutch hypothesis," Chest, vol. 126, no. 2, pp. 93S95S, 2004.

[36] H. Herrick, The Association of Breastfeeding and Childhood Asthma: Results from the 2005 North Carolina Child Health Assessment and Monitoring Program, State Center for Health Statistics North Carolina Division of Public Health, 152, 2007, http://www.schs.state.nc.us/SCHS/.

[37] S. Halken and A. Høst, "Primary prevention of food allergy in infants who are at risk," Current Opinion in Allergy and Clinical Immunology, vol. 5, no. 3, pp. 255-259, 2005.

[38] I. Kull, C. Almqvist, G. Lilja, G. Pershagen, and M. Wickman, "Breast-feeding reduces the risk of asthma during the first 4 years of life," Journal of Allergy and Clinical Immunology, vol. 115, pp. 1324-1325, 2004.

[39] Y. Takemura, Y. Sakurai, S. Honjo et al., "Relation between breastfeeding and the prevalence of asthma: the Tokorozawa childhood asthma and pollinosis study," American Journal of Epidemiology, vol. 154, no. 2, pp. 115-119, 2001.

[40] M. Hamosh, "Protective function of proteins and lipids in human milk," Biology of the Neonate, vol. 74, no. 2, pp. 163176, 1998.

[41] C. B. Wilson, D. B. Lewis, and L. A. Penix, "The physiologic immunodeficiency of immaturity," in Immunologic Disorders of Infants and Children, E. R. Stiehm, Ed., pp. 253-295, Saunders, Philadelphia, Pa, USA, 1996.

[42] A. E. Wold and I. Adlerberth, "Does breastfeeding affect the infant's immune responsiveness?" Acta Paediatrica, vol. 87, no. 1, pp. 19-22, 1998.

[43] M. Xanthou, "Immune protection of human milk," Biology of the Neonate, vol. 74, no. 2, pp. 121-133, 1998.

[44] A. Sherriff, T. J. Peters, J. Henderson, and D. Strachan, "Risk factor associations with wheezing patterns in children followed longitudinally from birth to $31 / 2$ years," International Journal of Epidemiology, vol. 30, no. 6, pp. 1473-1484, 2001.

[45] B. A. Raby, K. Van Steen, J. C. Celedón, A. A. Litonjua, C. Lange, and S. T. Weiss, "Paternal history of asthma and airway 
responsiveness in children with asthma," American Journal of Respiratory and Critical Care Medicine, vol. 172, no. 5, pp. 552-558, 2005.

[46] M. Hibbert, A. Lannigan, J. Raven, L. Landau, and P. Phelan, "Gender differences in lung growth," Pediatric Pulmonology, vol. 19, no. 2, pp. 129-134, 1995.

[47] J. L. Hopper, M. E. Hibbert, G. T. Macaskill, P. D. Phelan, and L. I. Landau, "Longitudinal analysis of lung function growth in healthy children and adolescents," Journal of Applied Physiology, vol. 70, no. 2, pp. 770-777, 1991.

[48] G. Zhang, J. Spickett, K. Rumchev, A. H. Lee, and S. Stick, "Snoring in primary school children and domestic environment: a Perth school based study," Respiratory Research, vol. 5, no. 19, 2004.

[49] L. R. Lu, J. K. Peat, and C. E. Sullivan, "Snoring in preschool children: prevalence and association with nocturnal cough and asthma," Chest, vol. 124, no. 2, pp. 587-593, 2003.

[50] D. B. Teculescu, I. Caillier, P. Perrin, E. Rebstock, and A. Rauch, "Snoring in French preschool children," Pediatric Pulmonology, vol. 13, no. 4, pp. 239-244, 1992.

[51] M. F. Fitzpatrick, K. Martin, E. Fossey, C. M. Shapiro, R. A. Elton, and N. J. Douglas, "Snoring, asthma and sleep disturbance in Britian: a community-based survey," European Respiratory Journal, vol. 6, no. 4, pp. 531-535, 1993.

[52] H. V. Villar, P. H. Edwards, D. C. Lauff, M. Berthon-Jones, and C. E. Sullivan, "Tracheal smooth muscle responses to upper airway pressure in conscious dogs," Journal of Applied Physiology, vol. 68, no. 4, pp. 1555-1561, 1990.

[53] J. J. K. Jaakkola, B. F. Hwang, and N. Jaakkola, "Home dampness and molds, parental atopy, and asthma in childhood: a six-year population-based cohort study," Environmental Health Perspectives, vol. 113, no. 3, pp. 357-361, 2005.

[54] J. D. Spengler, L. Neas, D. W. Dockery, F. Speizer, J. Ware, and M. Raizanne, "Respiratory symptoms and housing characteristics," Indoor Air, vol. 4, pp. 72-82, 1994.

[55] C. Y. Yang, J. F. Chiu, M. F. Cheng, and M. C. Lin, "Effects of indoor environmental factors on respiratory health of children in a subtropical climate," Environmental Research, vol. 75, no. 1, pp. 49-55, 1997.

[56] C. G. Bornehag, "Dampness in buildings and health nordic interdisciplinary review of the scientific evidence on associations between exposure to "dampness" in buildings and health effects (NORDDAMP)," Indoor Air, vol. 11, no. 2, pp. 72-86, 2001.

[57] E. Johanning, P. Landsbergis, M. Gareis, C. S. Yang, and E. Olmsted, "Clinical experience and results of a sentinel health investigation related to indoor fungal exposure," Environmental Health Perspectives, vol. 107, no. 3, pp. 489-494, 1999.

[58] D. Norbäck, E. Björnsson, C. Janson, U. Palmgren, and G. Boman, "Current asthma and biochemical signs of inflammation in relation to building dampness in dwellings," International Journal of Tuberculosis and Lung Disease, vol. 3, no. 5, pp. 368-376, 1999.

[59] H. F. Kauffman and S. van der Heide, "Exposure, sensitization, and mechanisms of fungus-induced asthma," Current Allergy and Asthma Reports, vol. 3, no. 5, pp. 430-437, 2003.

[60] M. Cheraghi and S. Salvi, "Environmental tobacco smoke (ETS) and respiratory health in children," European Journal of Pediatrics, vol. 168, no. 8, pp. 897-905, 2009. 


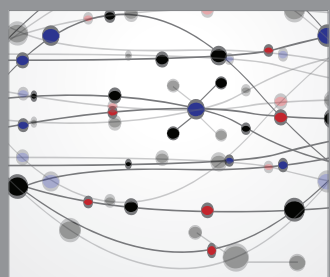

The Scientific World Journal
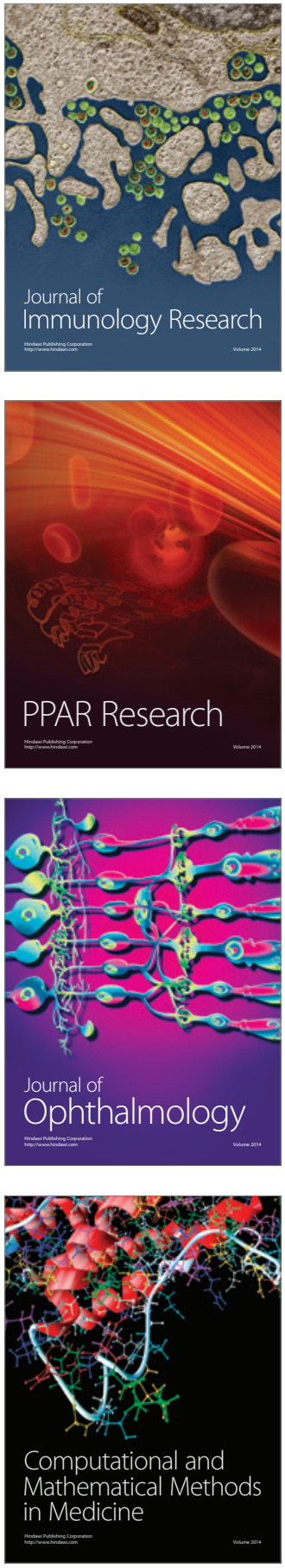

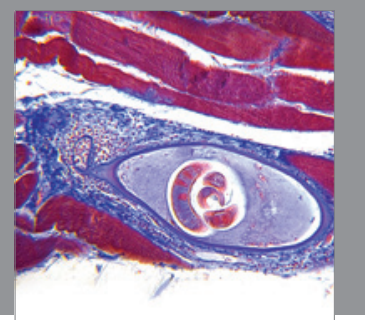

Gastroenterology

Research and Practice
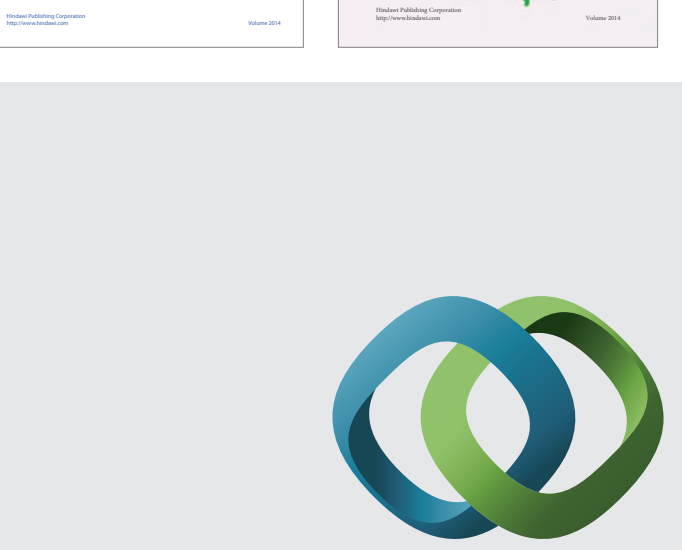

\section{Hindawi}

Submit your manuscripts at

http://www.hindawi.com
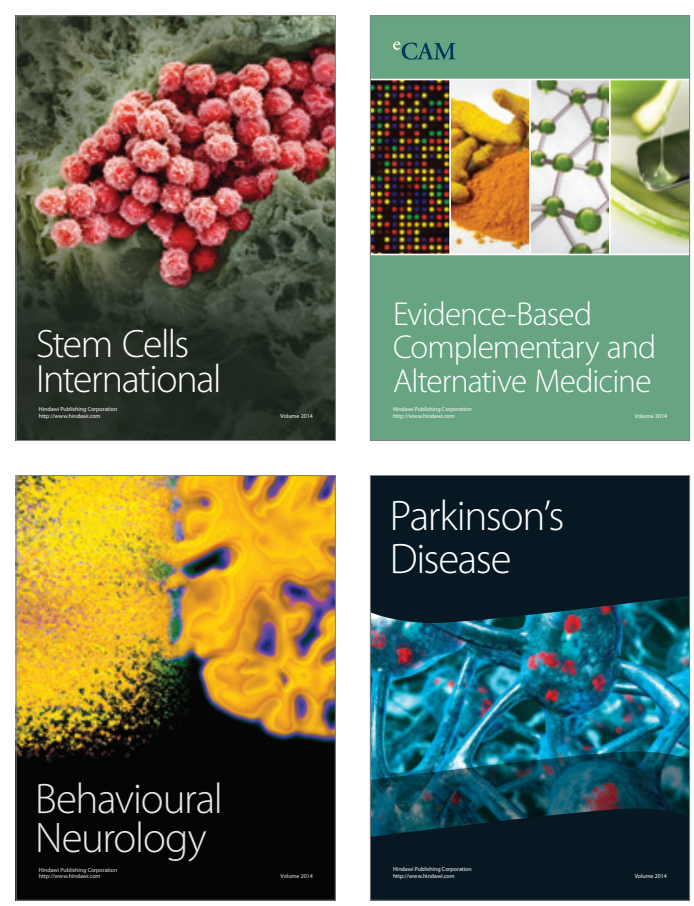

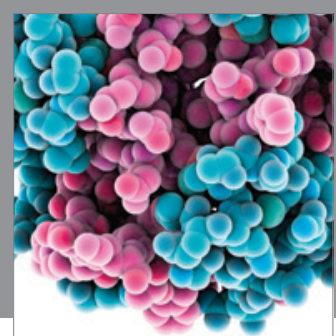

Journal of
Diabetes Research

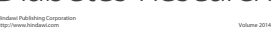

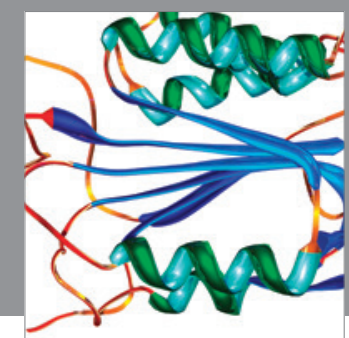

Disease Markers
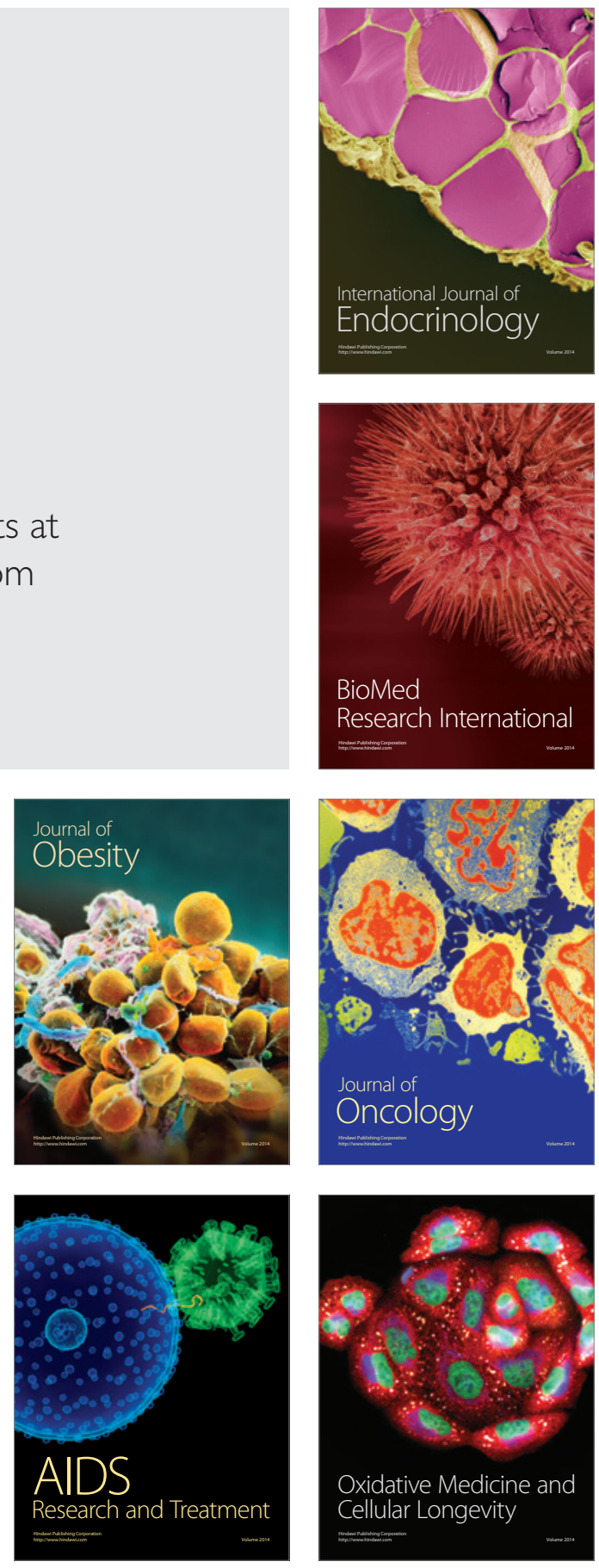